\title{
Aerostructural Model for Morphing Laminar Wing Optimization in a Wind Tunnel
}

\author{
Daniel Coutu, $\stackrel{*}{*}$ Vladimir Brailovski,, \pm and Patrick Terriault $\stackrel{\ddagger}{ \pm}$ \\ École de Technologie Supérieure, Montréal, Québec H3C 1K3, Canada \\ and

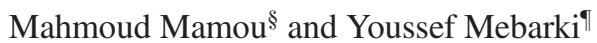 \\ National Research Council, Ottawa, Ontario K1A 0R6, Canada
}

DOI: $\underline{10.2514 / 1 . C 000232}$

\begin{abstract}
An aerostructural numerical model of a two-dimensional morphing laminar wing prototype is built and validated for different flight conditions: Mach numbers ranging from 0.2 to 0.3 and angles of attack ranging from -1 to $2^{\circ}$. The active structure of the wing is modeled using the ANSYS commercial finite element software. The aerostructural interaction is achieved by coupling the XFoil free-license aerodynamic solver to ANSYS. This model is used to minimize the drag force under constant-lift conditions during wind-tunnel testing using a two-step optimization algorithm (global and local search). The wake pressure wind-tunnel measurements show that extrados morphing results in an average $18.5 \%$ drag reduction for eight flow cases covering the flow condition range of interest. Simultaneously, the infrared thermography measurements record an average laminar flow extension of $25 \%$ of the wing chord over the upper wing surface. The experimental and numerical results are in good agreement, thus validating the use of an aerostructural model to efficiently manage the shape of a morphing laminar wing.
\end{abstract}

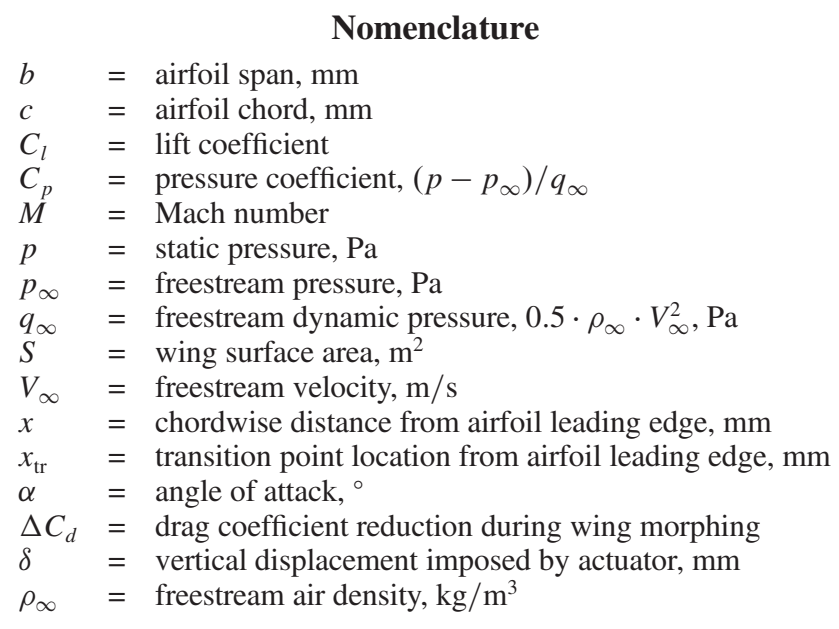

\section{Introduction}

$\mathbf{E}$ NVIRONMENTAL concerns have led to calls for cleaner and quieter aircraft and for diminishing the aviation industry's dependence on petroleum. Based on the study performed by the International Council on Clean Transportation [1], average fuel consumption (on both a seat $\cdot \mathrm{km}$ and ton $\cdot \mathrm{km}$ basis) of commercial jet aircraft was reduced by $51 \%$ from 1960 to 2008. It is claimed that the introduction of widebody aircraft and high-bypass-ratio turbofans are the two major breakthrough technologies that have

Received 18 December 2009; revision received 16 July 2010; accepted for publication 9 November 2010. Copyright @ 2010 by the American Institute of Aeronautics and Astronautics, Inc. All rights reserved. Copies of this paper may be made for personal or internal use, on condition that the copier pay the $\$ 10.00$ per-copy fee to the Copyright Clearance Center, Inc., 222 Rosewood Drive, Danvers, MA 01923; include the code 0021-8669/11 and $\$ 10.00$ in correspondence with the CCC.

*Ph.D. Candidate, Mechanical Engineering, 1100 Notre-Dame Street West.

†Professor, Mechanical Engineering, 1100 Notre-Dame Street West; vbrailovski@mec.etsmtl.ca (Corresponding Author).

${ }^{\ddagger}$ Professor, Mechanical Engineering. 1100 Notre-Dame Street West.

${ }^{\S}$ Associate Research Officer, Institute of Aerospace Research, NRC.

๑Aerodynamics Research Officer, Institute of Aerospace Research. contributed to the doubling of the average efficiency of aircraft in the past 50 years.

The International Air Transport Association [2] predicts that morphing wings will be one of the next breakthrough technologies, thanks to the availability of higher fidelity numerical models and the increasing use of composite materials. Even now, an increasing number of morphing wing concepts, such as the FlexSys mission adaptative compliant wing (MACW), the NextGen batwing morphing concept, and the NASA morphing aircraft are appearing in the literature [3]. Four years ago, the Consortium for Research and Innovation in Aerospace in Quebec (CRIAQ) initiated a research project to demonstrate the feasibility of the morphing wing technology to extend the laminar flow on the wing upper surface under subsonic cruise flight conditions (CRIAQ7.1) [4]. This project was completed in 2009, with the results [5-12] offering new perspectives for the development of such morphing technology at higher technology readiness levels (TRLs) $(5<\mathrm{TRL}<6)$.

In the framework of the CRIAQ7.1 project, an experimental morphing laminar wing (MLW) with a 500-mm-chord length and a 990.6-mm-span length was designed, manufactured, and tested in a subsonic wind tunnel. The concept is shown in Fig. 1, and it consists of a supercritical airfoil with a flexible extrados capable of adapting its shape to the variable flow conditions in order to increase the natural laminar flow over the wing's upper surface. The flow conditions of interest ranged from Mach numbers 0.2 to 0.3 (in 0.025 increments), and the angles of attack varied between -1 and $2^{\circ}$ (in $0.5^{\circ}$ increments), for a total of 35 cases. The flexible extrados was made from a four-ply composite laminate shell attached to the leading edge and to a compensation spring at the aft end to ensure profile tangency. Two linear-shaped memory alloy (SMA) actuators were used to morph the two-dimensional wing profile. The number of actuators and the number of plies were two independent design variables chosen to offer the best tradeoff between the aerodynamic performance of the morphing wing and the mechanical work provided by the actuation system to morph the extrados. This multicriterion optimization task was performed using the ANSYS finite element software and the XFoil aerodynamic flow solver [5]. The experimental MLW was assembled and tested in the subsonic wind tunnel located at the Institute for Aerospace Research of the National Research Council, Canada (NRC)..** This closed-circuit

**Data available at http://www.nrc-cnrc.gc.ca/eng/facilities/iar/2x3/ technical.html [retrieved 10 May 2010]. 


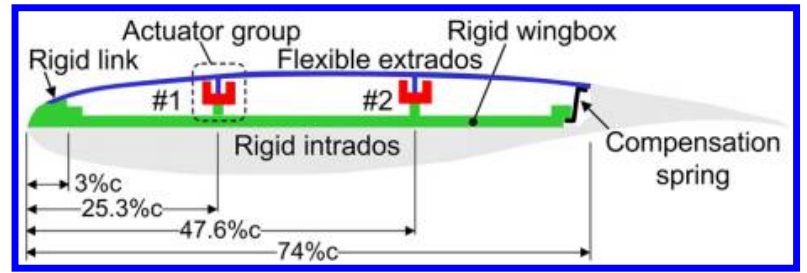

Fig. 1 MLW concept with active extrados [6].

wind tunnel has a $2 \times 3 \mathrm{~m}$ test section operating under atmospheric conditions with speed uniformity of $\pm 0.07 \%$ and $0.14 \%$ turbulence intensity.

When a morphing wing prototype is tested in a wind tunnel or in flight, the wing shape may be controlled using either open-loop or closed-loop approaches. Generally, an open-loop control approach is used to characterize structural integrity (Lockheed Martin morphing aircraft [13]) or aeroelastic behavior (NextGen morphing aircraft structure [14]) of a developed morphing wing concept. In both of the previously mentioned cases, the morphing wing prototypes were successfully tested in the NASA Langley Research Center Transonic Dynamics Tunnel for several morphing configurations using openloop controllers.

To control the shape of a morphing wing prototype in flight, both types of controllers can also be used. For example, two open-loop control techniques have been proposed to optimize the shape of a morphing wing. The first technique relies on a design-of-experiment (DOE) approach. To find the best trailing-edge morphing flap deflection that minimizes the lift-to-drag ratio, the MACW of Hetrick et al. [15] was tested during $27 \mathrm{~h}$ of flight. The open-loop controller repetitively commanded a significant set of morphing configurations over the range of flight conditions of interest. From the results, the authors pretend that MACW can achieve a $15 \%$ increase in aircraft endurance by continuously optimizing the lift-to-drag ratio. The major drawback of such a procedure is that a large amount of time is required to pass through the test matrix. The DOE approach was not compatible with the CRIAQ7.1 budget available for wind-tunnel testing, with its 35 flow conditions to be studied, and was therefore rejected.

The second open-loop optimization technique relies on the predictions of a numerical model. Strelec et al. [16] used an aerothermomechanical model to optimize the design variables of their SMA actuated reconfigurable airfoil in order to maximize the lift-to-drag ratio for $3^{\circ}$-angle-of-attack subsonic flow conditions. Tested in a low-speed wind tunnel, the wing was actuated to the single deformed configuration using an open-loop controller. Unfortunately, the measured aerodynamic performance was less than expected due to prototype manufacturing issues.
However, to optimize the shape of a morphing wing prototype in flight, the closed-loop control approach appears to be more beneficial, because it uses hardware in the loop to continuously measure the wing performance. One of the first relevant examples of this approach is the wind-tunnel test of a computer-controlled selfoptimizing flexible technology wing model. This work, realized by Levinsky and Palko in 1979 [17], used the wind-tunnel balance to close the loop and an iterative algorithm to optimize the stroke of six actuators that control the wing shape. A nearly $10 \%$ drag reduction was achieved in the transonic wind tunnel at constant-lift conditions. In the field of micro air vehicles, Boria et al. [18] also used this approach to maximize the lift-to-drag ratio of the morphing Zimmerman planform wing. However, despite the positive results obtained, the authors concluded that, given the inherent complexity of the hardware in the loop, an open-loop approach could have led to similar results.

This work is limited to an open-loop morphing wing control approach as a first step in the development of a MLW control strategy. A closed-loop MLW control approach was tested by the authors, and the results obtained are submitted for publication elsewhere $[11,12]$. In the following sections, a structural finite element model (A $\overline{N S} \overline{Y S}$ ) and an aerodynamic two-dimensional panel method code with integral boundary-layer theory (XFoil) are presented separately and then in a coupled formulation. First, an overview of the ANSYS model and its validation under wind-off conditions is given. Then, to evaluate the effect of the finite-element-model (FEM) discrepancies on the aerodynamic performance predictions, the XFoil 6.96 aerodynamic solver is used. The aerostructural interaction uses windtunnel empirical correlation data to apply true aerodynamic loads over the flexible extrados. A convergence study of the aerostructural model is performed, and the results obtained are validated by the wind-tunnel-measured aerodynamic pressure distributions over the prototype extrados. To find the actuator strokes that maximize the aerodynamic performance of the MLW prototype, a two-step optimization procedure using the aerostructural model is discussed. The first step is based on a generalized pattern search using a MATLAB-supported algorithm, and the second step uses a local search algorithm specifically developed for this application. Furthermore, wind-tunnel-measured balance forces, wake pressures, and infrared (IR) thermography data are compared with the numerically predicted results. Finally, recommendations are drawn and extrapolated to real aircraft applications.

\section{Structural Finite Element Model}

The FEM of the flexible structure, built in ANSYS software, includes spanwise stiffeners and several transmission components, such as pivot axes and cranks (see Fig. 2).

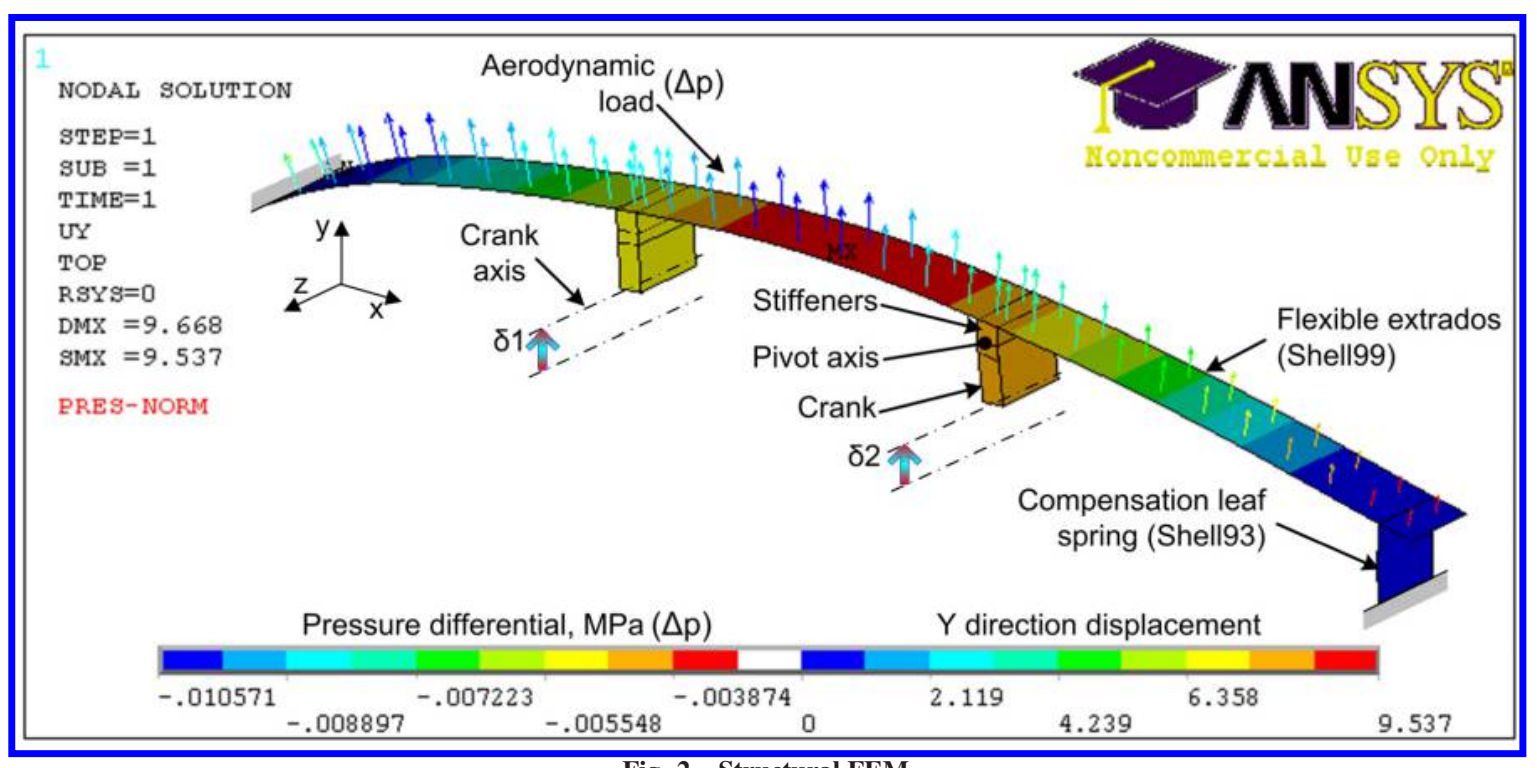

Fig. 2 Structural FEM. 


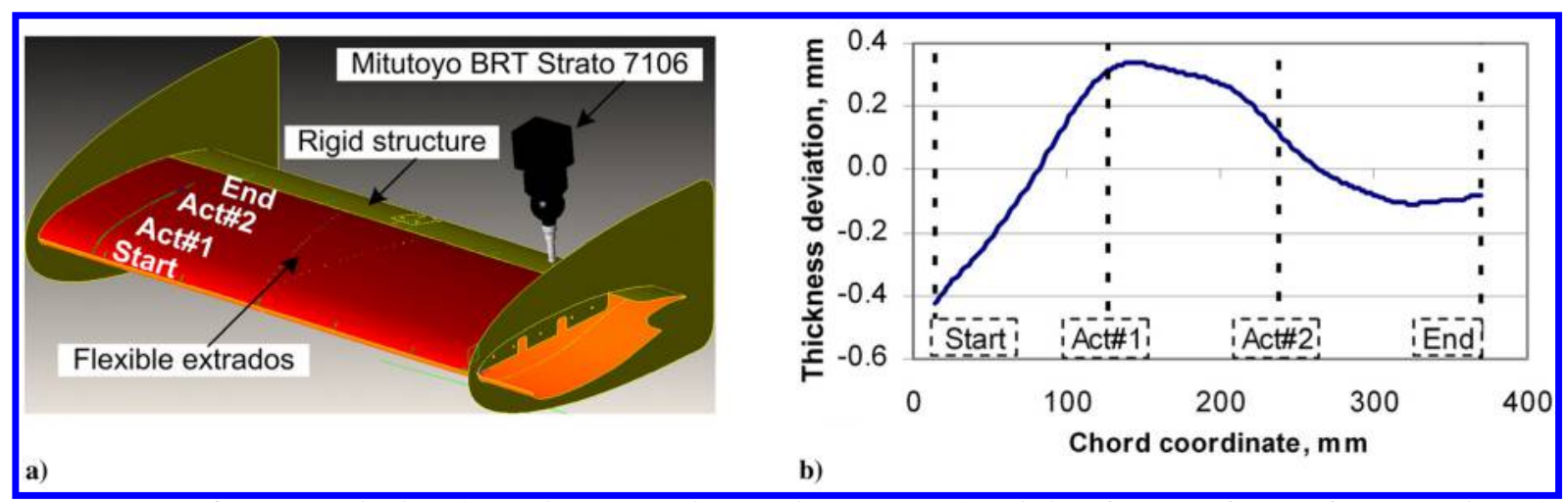

Fig. 3 Unmorphed profile characterization: a) coordinate measuring machine setup and b) deviation of the manufactured from the designed (targeted) reference profile.

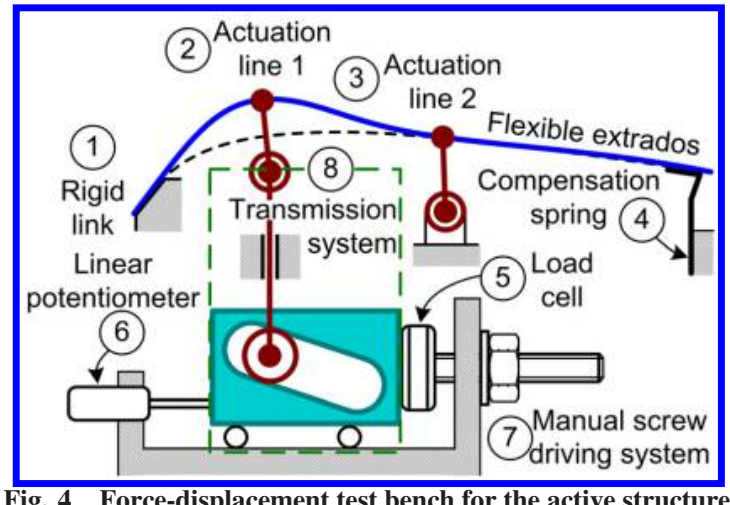

Fig. 4 Force-displacement test bench for the active structure.

\section{A. Validation of Reference Prototype Geometry}

The unmorphed geometry of the manufactured prototype was measured using a Mitutoyo BRT-Strato 7106 coordinate-measuring machine (Fig. 3a) and then compared with the targeted geometry (see Fig. 3b) to implement the measured deviations into the structural FEM solver.

\section{B. Validation of Finite-Element-Model Force-Displacement Response}

To ensure that the flexible-structure FEM is accurate in terms of its structural response, its force-displacement behavior was verified experimentally. Figure 4 presents a schematic illustration of the test bench containing the flexible structure with four anchor points: the rigid link (1), two actuator lines (2 and 3 ), and a compensation spring (4). Displacements of the flexible structure were measured using a linear potentiometer (6). The SMA actuation system was replaced by a manual screwdriving system (7) containing a load cell (5) to measure the actuation force.

The force-displacement curves presented in Figs. 5a and 5b were obtained by driving one actuation line between its displacement limits while restraining another actuation line. The forcedisplacement response of the active structure (EXP_act1\&2) was compared with the numerical predictions (FE_act1\&2). It can be observed that the model adequately predicts the overall behavior of the flexible extrados, except for the hysteresis caused by friction in the power transmission system. Consequently, the load-free position of each actuation line at the end of the loading-unloading cycle does not correspond to zero, and a negative force of nearly $100 \mathrm{~N}$ must be applied to return the extrados to its reference position. Considering that the SMA actuation system is displacement-controlled in using a linear potentiometer feedback signal, the SMA wire heating and cooling temperatures are automatically regulated to compensate for the mechanical hysteresis [10].

C. Validation of Finite-Element-Model Shape Modification Response Under Actuation

To validate the numerical model in terms of its ability to predict the shape modifications of the active structure, a custom-designed laser profilometer was built (see Fig. 6a). The coordinates of the extrados profile were collected using two measuring devices: an optical shaft encoder (Sumtak LBL-015-1000) and a mobile laser displacement sensor (Wenglor CP35MHT80), aligned along the chord $X$ and the thickness $Z$ axes of the wing, respectively. Thickness modifications under actuation were measured experimentally and calculated numerically by subtracting the unmorphed profile coordinates form the morphed profile coordinates (see the two upper curves in Fig. 6b). The deviations (see the two lower curves in Fig. 6b) were obtained by subtracting the experimental thickness modifications from those

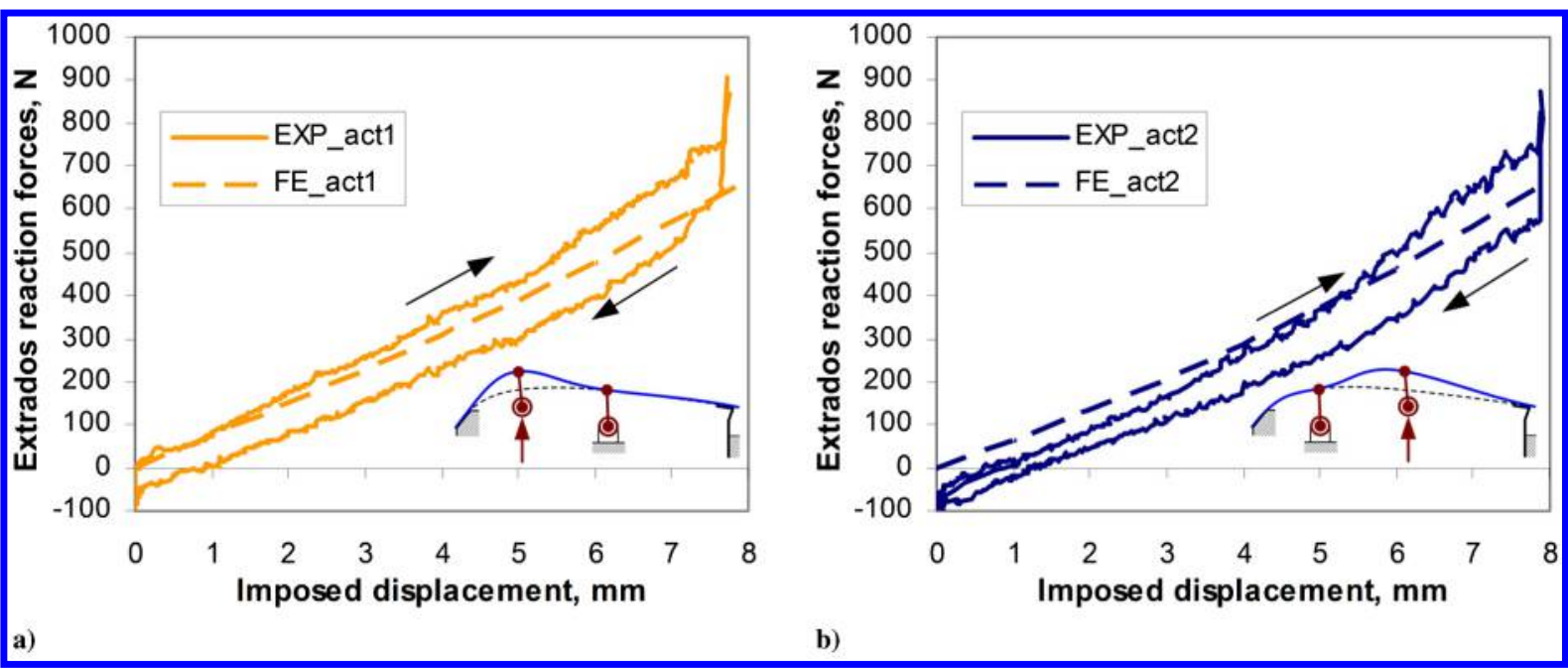

Fig. 5 Force-displacement diagrams: a) first and b) second actuation lines (EXP: experimental; FE: calculated data). 


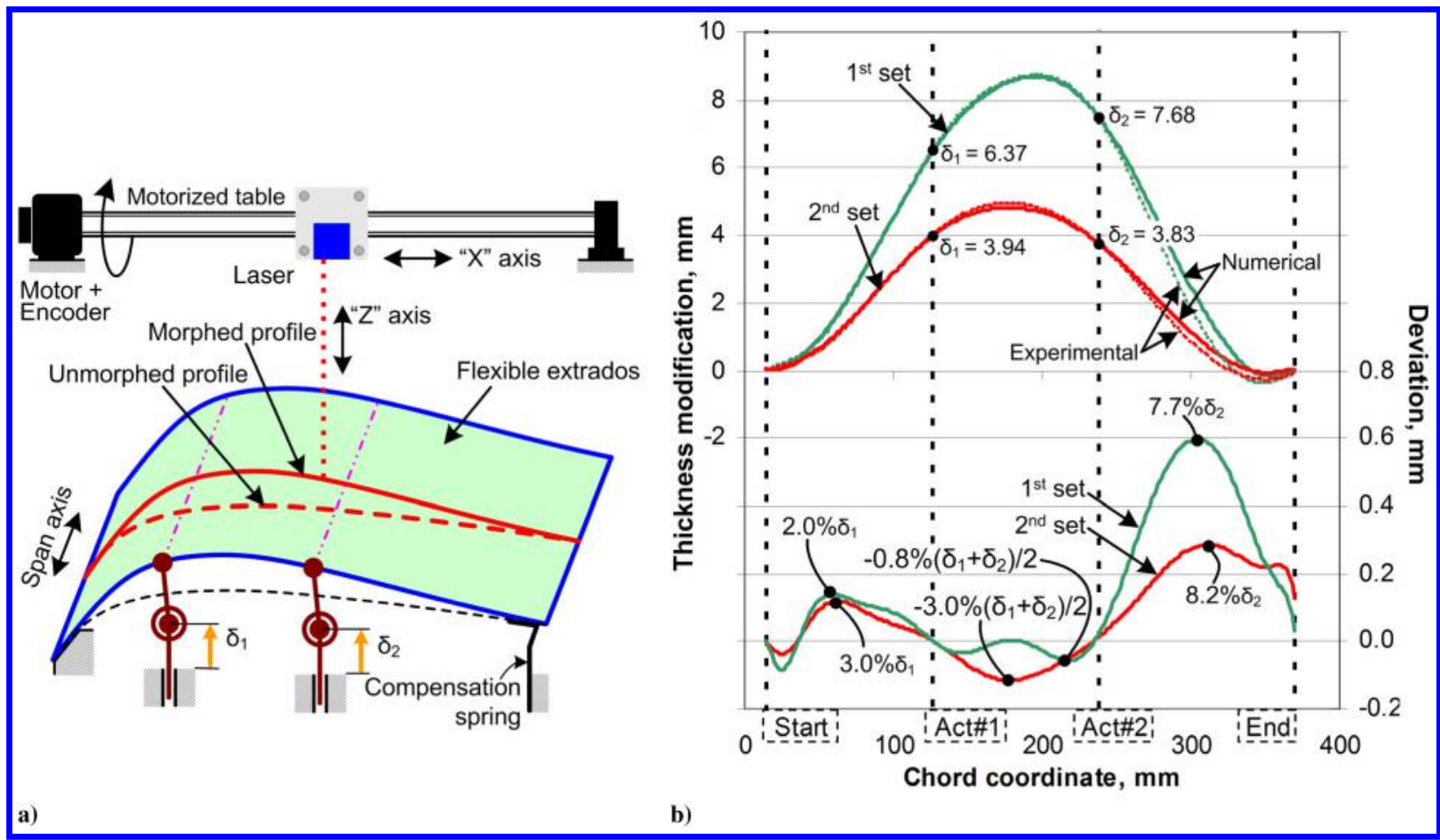

Fig. 6 Validation of the shape modification for two sets of actuator displacements: a) bench test setup, and b) comparison of the numerical and experimental thickness modifications.

predicted numerically. Two sets of actuator displacements were used for this validation. First, the SMA actuators deformed the extrados close to the full stroke of $8 \mathrm{~mm}$ (first set: $\delta_{1}=6.37$ and $\delta_{2}=7.68$ ). The displacements were then adjusted to approximately one half of the previous values (second set: $\delta_{1}=3.94$ and $\delta_{2}=3.83$ ). As can be observed in Fig. 6b, the geometrical deviations vary between -0.12 and $+0.14 \mathrm{~mm}$ for the first $250 \mathrm{~mm}$ of the chord length and reach $+0.59 \mathrm{~mm}$ closer to the aft end of the flexible extrados. For each portion of the chord delimited by the flexible extrados attachment points, the minimum or maximum numerical thickness deviations are given as a percentile of the applied strokes: $\delta_{1},\left(\delta_{1}+\delta_{2}\right) / 2$, or $\delta_{2}$.

\section{Aerodynamic Effects of Deviations Between}

Finite-Element-Model Predictions and Experiments

To quantify the effect of deviations between structural model predictions and experiments on the aerodynamic performance of the wing prototype, computational fluid dynamic analyses were carried out using XFoil 6.96 [19]. This code, written by Mark Drela in 1986, uses a high-resolution panel method with a Karman-Tsien compressibility correction. The resulting inviscid solution is incorporated

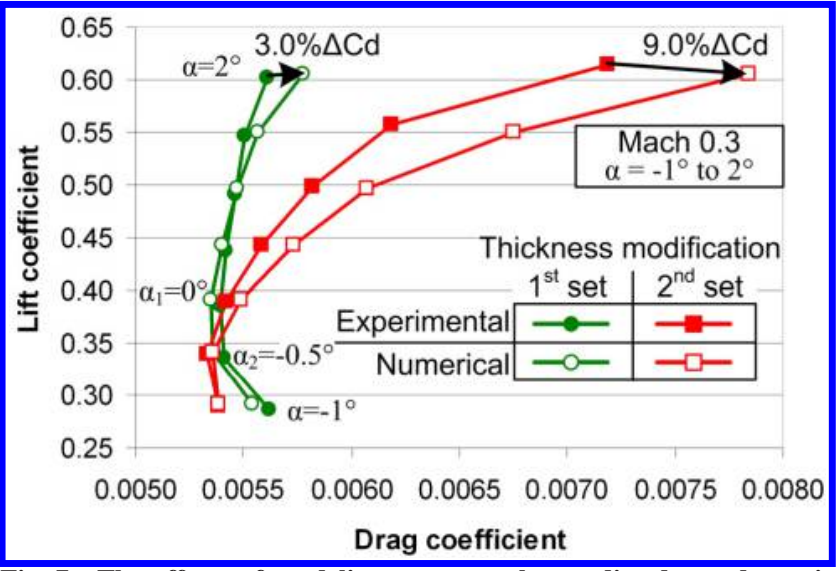

Fig. 7 The effects of modeling error on the predicted aerodynamic performance for the first and second sets of actuator displacements (see also Fig. 6b). into the viscous equations and solved by the full-Newton method. For low angles of attack or lift coefficients $\left(C_{l}<C_{l \max }\right)$, the solver provides reasonably accurate drag and $C p$ distribution for Mach numbers below 1.05, which works well for this study (Mach number of 0.3). Moreover, from the viscous solution, the laminar-toturbulent transition is predicted using a simplified $e^{N}$ method with the $N$ factor fixed to seven, a value representative of the turbulence level of the NRC wind-tunnel incoming flow [20].

Figure 7 shows the XFoil-calculated polar curves for the experimentally measured and calculated profiles for the first and second sets of actuator displacements for angles of attack varying from -1 to $2^{\circ}$, with $0.5^{\circ}$ increments, and the highest Mach number of 0.3 (see Fig. 6b). Generally speaking, the effects of the modeling errors on the aerodynamic performance calculations decreased as the drag coefficient decreased. The largest difference in terms of drag coefficient (a 9.0\% shift) was observed for the second set of actuator displacements, and it corresponds to the highest Mach number and angle of attack (Mach 0.3 and $\alpha=2^{\circ}$ ). This result could be expected since the second set of displacements corresponds to the greatest thickness deviations between the flexible extrados attachment points: $+3.0 \% \delta_{1}, 3.0 \%\left(\delta_{1}+\delta_{2}\right) / 2$, and $+8.2 \% \delta_{2}$. The differences in terms of lift coefficient are less significant, and the largest value shows a $1.9 \%$ shift for the first set of displacements at Mach 0.3 and $\alpha=-1^{\circ}$.

Although the modeling errors affected the predictions of the morphing wing aerodynamic performance, the structural FEM appears to be suitable for the optimal strokes calculations. Indeed, Fig. 7 shows that, for both sets of actuator displacements, the angles of attack that minimize the drag for Mach number 0.3 are the same ( $\alpha_{1}=0$ for the first set, and $\alpha_{2}=-0.5^{\circ}$ for the second set) whether the profile deviations are considered or not. Therefore, the structural model can be considered ready to be coupled to an aerodynamic solver to assess the aerostructural interaction.

\section{Aerostructural Model and its Wind-Tunnel Validation}

\section{A. Preliminary Works}

Since the extrados morphing affects aerodynamic pressure distribution over the MLW, and the aerodynamic pressure distribution affects the extrados geometry, the aerostructural interaction must be 


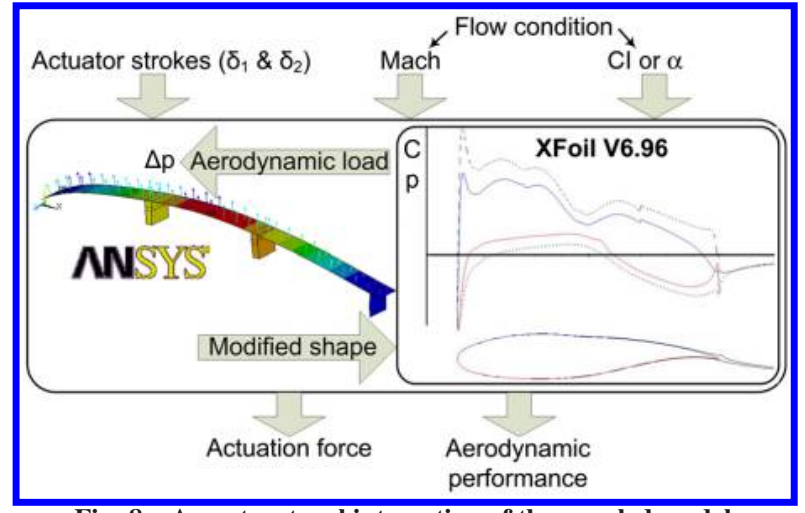

Fig. 8 Aerostructural interaction of the coupled model.

modeled. XFoil software is well suited to be coupled to the ANSYS structural model due to its short execution time and its capability to be launched from an external command line. Note that at the very beginning of the CRIAQ7.1 project, XFoil was already being used by our collaborators from École Polytechnique de Montréal to generate a series of optimized airfoil profiles and to establish the technical requirements for the MLW [21].

\section{B. Aerostructural Interaction}

The aerostructural coupling between the structural FEM and the aerodynamic solver XFoil was achieved with an iterative algorithm coded in ANSYS parametric design language. As sketched in Fig. 8 , for a given set of actuator strokes and flow conditions, the coupled model solves a steady-state problem to calculate the aerodynamic performance and actuation forces (the latter were used for SMA actuator design; see Georges et al. [9]). Actuator strokes are applied as vertical displacements of the transmission crank axis, whereas a linear interpolation table is used for the aerodynamic load. To accelerate the convergence, the initial pressure distribution corresponds to that calculated by XFoil for each optimized profile, without considering any aerostructural interaction [21]. Subsequently, the nonlinear structural problem is solved with ANSYS, and the aerodynamic performance of the resulting modified shape is

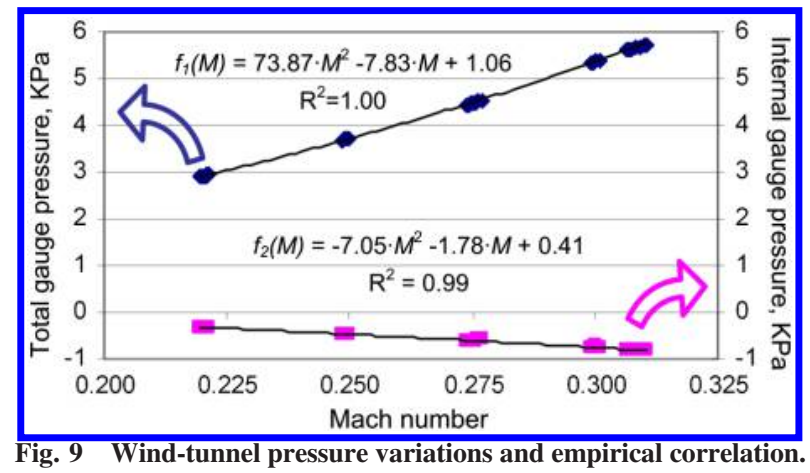

evaluated by XFoil. To favor an accurate viscous solution, XFoil repanels the airfoil using splines generated from the FEM node coordinates. During subsequent iterations, the ANSYS routine uses the previously calculated XFoil pressure distribution to update the pressure load interpolation table.

\section{Empirical Correlation for Pressure Loading}

The pressure load $\Delta p$ is defined by Eq. (1) as a difference between the external $p_{\text {ext }}$ and internal $p_{\text {int }}$ pressures applied to the active structure. Given that the external pressure is directly related to the pressure distribution $C p$, a new load formulation can be derived from the dynamic $q_{\infty}$ and the total $p_{\text {tot }}$ pressure data [see Eqs. (2) and (3)]. Preliminary wind-tunnel runs showed a significant pressure evolution as the Mach number increased. Given that the closedcircuit wind tunnel was vented to the atmospheric pressure, the higher the Mach $M$ number, the higher the total pressure and the lower the pressure inside the MLW prototype [see plots $f_{1}(M)$ and $f_{2}(M)$ in Fig. 9]. Empirical correlations were derived for the total $p_{\text {tot }_{\text {gauge }}}$ and the internal $p_{\text {int gauge }}$ pressure gauges, as shown in Eq. (4). Finally, the pressure load applied on the flexible extrados can be evaluated by Eq. (5), using both the $f_{1}(M)$ and the $f_{2}(M)$ correlation functions:

$$
\Delta p=p_{\mathrm{ext}}-p_{\mathrm{int}}
$$

$$
\begin{gathered}
p_{\mathrm{ext}}=q_{\infty}\left(C_{p}-1\right)+p_{\text {tot }} \\
\Delta p=q_{\infty}\left(C_{p}-1\right)+p_{\text {tot }}-p_{\text {int }} \\
p_{\text {tot }}-p_{\text {int }}=p_{\text {tot }_{\text {gauge }}}-p_{\text {int }_{\text {gauge }}}=f_{1}(M)-f_{2}(M) \\
\Delta p=q_{\infty}\left(C_{p}-1\right)+f_{1}(M)-f_{2}(M)
\end{gathered}
$$

\section{Aerostructural Convergence Study}

A convergence study was performed to determine the reasonable number of iterations required to achieve adequate aerostructural coupling. For this purpose, the highest pressure loading flow case was considered (Mach $0.3 ; C_{l}=0.602$ ), with actuator displacements close to the maximum $\left(\delta_{1}=6.70 \mathrm{~mm} ; \delta_{2}=7.95 \mathrm{~mm}\right)$. Figure $10 \mathrm{a}$ presents the maximum variations of the pressure load and shape modifications as percentiles of the values obtained in previous iterations, without regard to its sign, for the first 20 iterations. Separate convergence criteria were established for both parameters: pressure load convergence of $1 \%$ was reached at the third iteration, while shape modification convergence of $0.001 \%$ was reached at the fifth iteration. Therefore, the minimum number of iterations to ensure an adequate convergence of the coupled aerostructural model was set to five.
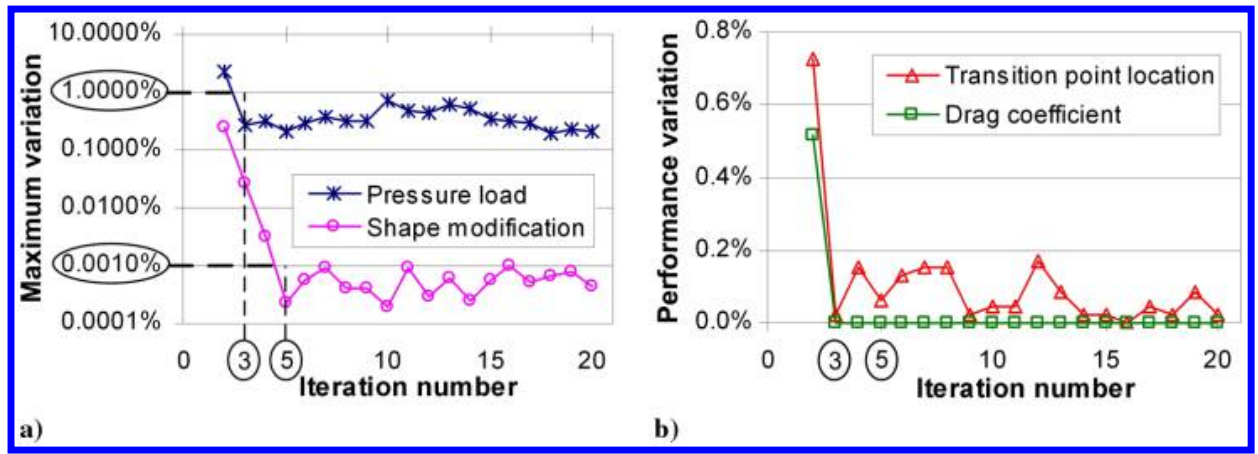

Fig. 10 Aerostructural convergence study: a) maximum absolute variation of the pressure load and shape modifications, and b) absolute variation of the drag coefficient and location of the laminar/turbulent transition. 
For verification, the absolute values of the variation (given as a percentile of the value of the previous iteration) of the drag coefficient and of the laminar/turbulent transition over the morphing extrados are presented in Fig. 10b for the first 20 iterations. After the third iteration, the drag prediction remains constant, whereas the transition point location varies between 46.4 and $46.5 \%$ of the chord length. These results are considered satisfactory, as the maximum variation of the transition prediction remains under $0.2 \%$ after the third iteration. Therefore, five iterations appear to be sufficient to ensure reliable aerostructural interaction.

When comparing two curves of Fig. 10a, the maximum pressure load variation $(\sim 1 \%)$ is about 1000 times greater than the maximum shape modification variation $(\sim 0.001 \%)$. This observation is coherent with the active structure design intent, wherein the numbers of plies and actuators were determined with the objective of ensuring sufficient stiffness in the flexible structure, thus limiting the sensitivity of the morphing structure to pressure load variations. Finally, small continuous variations (noise) in the aerostructural model response can be explained by the use of numerical interpolation methods and the limited number of significant digits used for data exchange between XFoil (six digits) and ANSYS (eight digits).

\section{E. Validation of Coupled Model in Terms of Pressure Distribution Calculations}

To validate the aerostructural model, the pressure distribution over the active structure extrados was experimentally measured and compared with the numerical predictions in Fig. 11. A pressure sensor array over the morphing extrados and a pressure port inside the model were used for this purpose. Unfortunately, during the installation, two reference pressure tubes near the leading edge were pinched accidentally. Consequently, the sharp pressure peak close to the leading edge could not be measured. Also, in the area before the first actuator line, where the flow suddenly accelerates and decelerates, numerical calculations overestimated the measured aerodynamic loads. Fortunately, on the remaining part of the morphing extrados, the numerical predictions were satisfactory. In summary, the pressure load prediction appears to be sufficiently
Table 1 Number of function evaluations per flow condition case for different optimization methods

\begin{tabular}{lc}
\hline \hline Optimization method & $\begin{array}{c}\text { No. of function } \\
\text { evaluations }\end{array}$ \\
\hline Full design search scan & 1681 \\
Two-step optimization & $\sim 127$ \\
Global optimization & $\sim 94$ \\
Local optimization & $\sim 33$ \\
\hline \hline
\end{tabular}

reliable to allow the use of the aerostructural model for MLW shape optimization.

\section{Actuator Stroke Optimization}

\section{A. Optimization Problem}

To find the best wing profile for each of the 35 flow cases, the actuator strokes were optimized using the aerostructural coupled model presented earlier. The profile drag under constant-lift conditions was selected as an objective function to minimize. Since shape morphing affects the profile lift, an appropriate adjustment of the angle of attack to keep the lift constant allows an objective comparison of the morphed and unmorphed profiles. Note that for subsonic flow, friction drag, which is the main component of the profile drag, decreases when the boundary layer is laminar instead of turbulent [22]. Therefore, an important laminar flow regime enhancement is expected from optimal wing morphing.

In this work, the design range for each actuator stroke lay between 0 and $8 \mathrm{~mm}$, the physical limits of the prototype. To devise an appropriate optimization method, the objective function was first calculated over the entire design range using $0.2 \mathrm{~mm}$ actuator stroke increments, for a total of 1681 points. Each point corresponded to a given set of two actuator strokes and required approximately $30 \mathrm{~s}$ of computation time (dual-core $2.0 \mathrm{GHz}$ desktop). For two particular flow cases $\left(M=0.25, \alpha=-1^{\circ}\right.$ and $\left.M=0.25, \alpha=0.5^{\circ}\right)$, the results

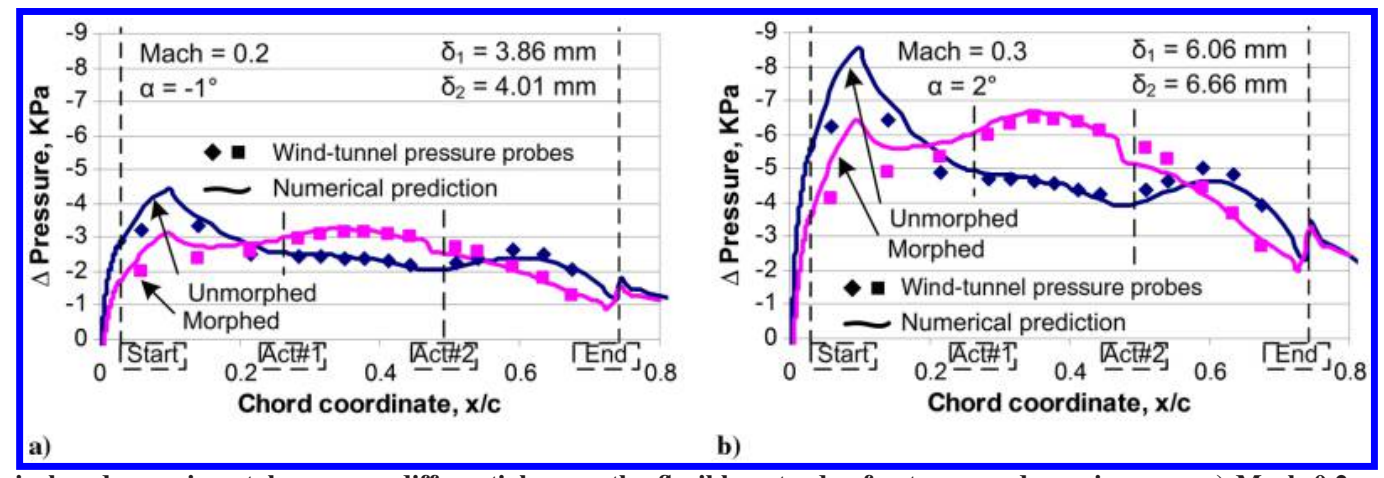

Fig. 11 Numerical and experimental pressure differentials over the flexible extrados for two aerodynamic cases: a) Mach 0.2 and $\alpha=-1^{\circ}$, and b) Mach 0.3 and $\alpha=2^{\circ}$.
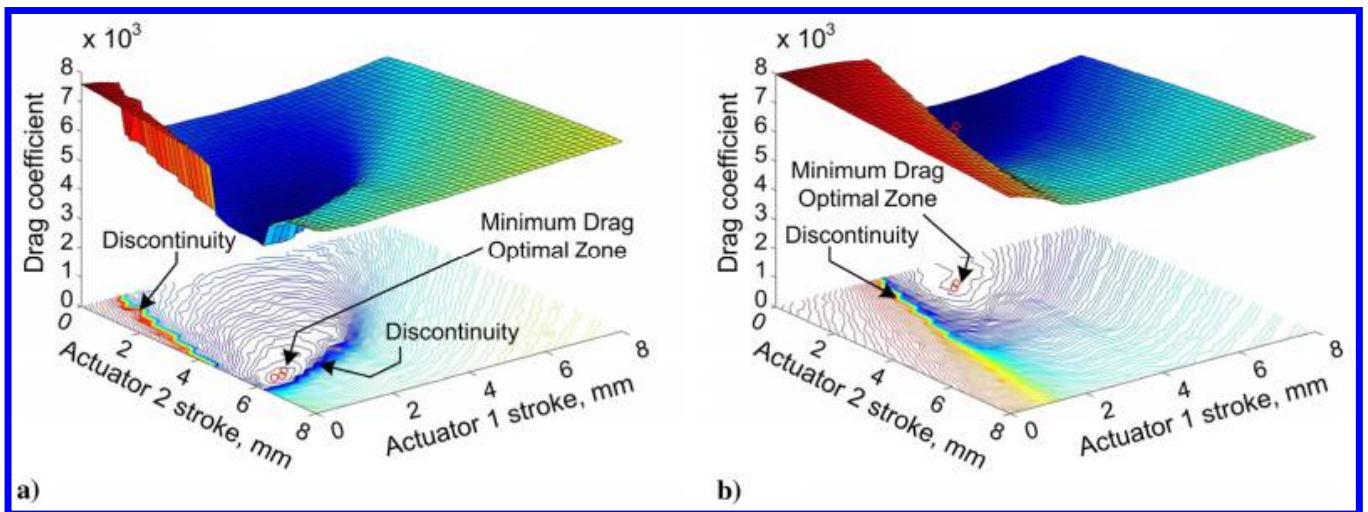

Fig. 12 Numerical drag coefficient responses for: a) Mach 0.25 and $\alpha=-1^{\circ}$, and b) Mach 0.25 and $\alpha=0.5^{\circ}$. 


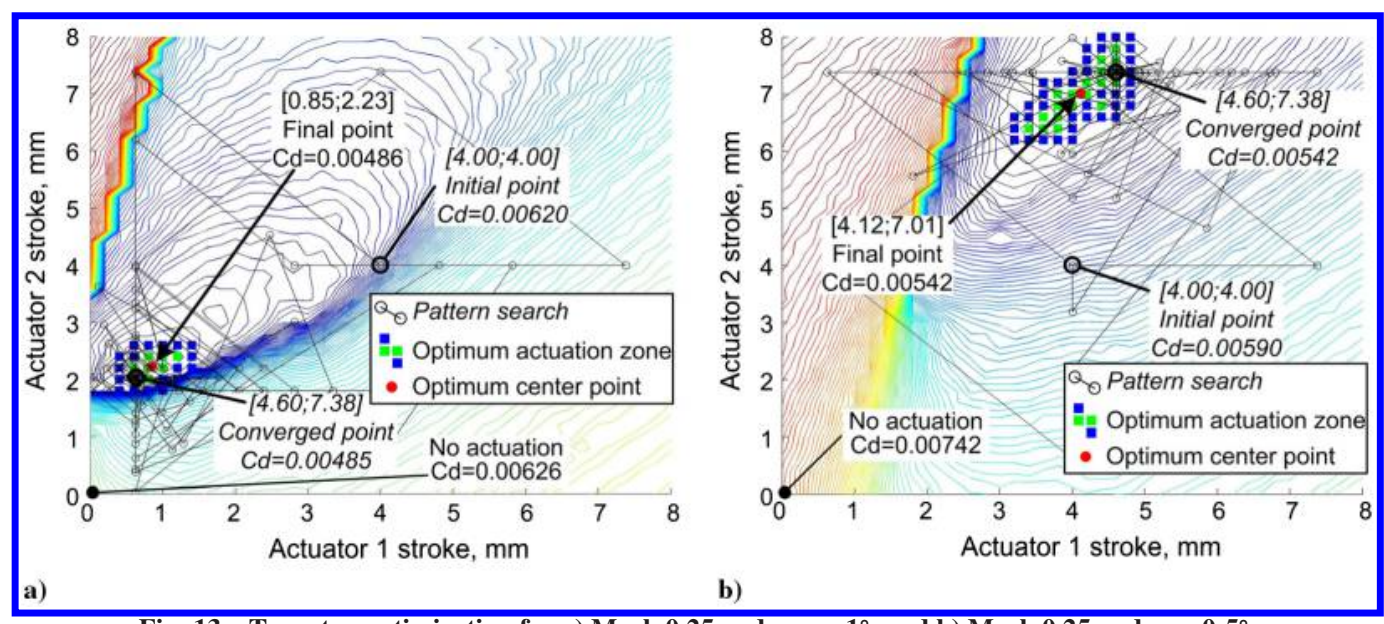

Fig. 13 Two-step optimization for a) Mach 0.25 and $\alpha=-1^{\circ}$, and b) Mach 0.25 and $\alpha=0.5^{\circ}$.

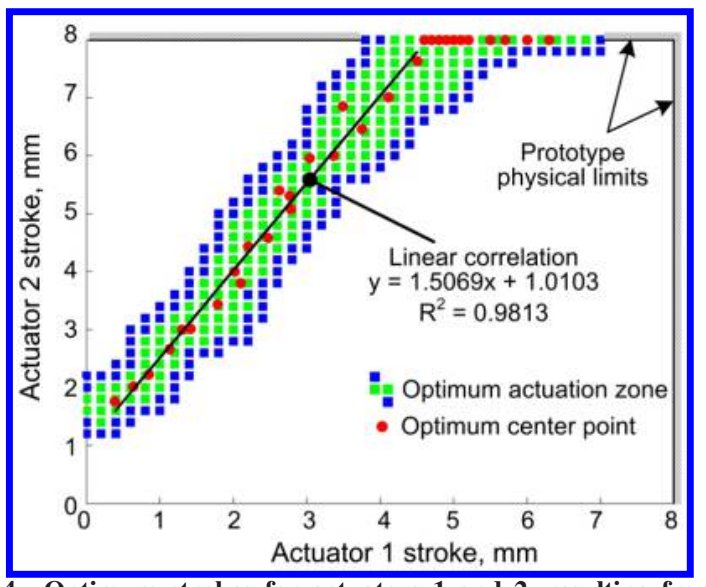

Fig. 14 Optimum strokes for actuators 1 and 2, resulting from the centers of the optimum zones.

of this full design search scan were plotted as response surfaces with their respective contour levels, as shown in Fig. 12. For both flow cases, the objective function presents several local minima that represent different optimal actuator strokes. Since the response surfaces calculation is a very costly task if it needs to be repeated for every possible flow condition (see Table 1 ), a two-step optimization procedure has been proposed [23]. The first step, called global or rough optimization, uses standard optimization algorithms to find a preliminary target point near the optimum zone, and the second step, called local optimization or fine tuning, uses a custom routine to determine the final optimum actuation stroke.

\section{B. Global Optimization}

The presence of discontinuities in the objective function (see Fig. 12) suggests that traditional search methods using the surface gradients are not well suited. Thus, a direct search algorithm, the generalized pattern search positive basis $2 N$, available in MATLAB [24], was selected and is presented as an example in Fig. 13. Using a client-defined pattern, this simple method searches among a set of points, thereby forming a mesh around a given point. The point that minimizes the objective function becomes the current point for the next iteration. The pattern search was executed in MATLAB with additional instructions, such as the actuation limits $(0-8 \mathrm{~mm})$ and the initial searching point, corresponding to half of the maximum actuator stroke $\left(\delta_{1}=\delta_{2}=4 \mathrm{~mm}\right)$.

Stopping criteria were adjusted so that the algorithm would stop when the distance between two consecutive points became smaller than $0.024 \mathrm{~mm}$ or when the number of iterations reached 100. Each evaluation was kept in memory by the algorithm to avoid recomputing points located within $0.01 \mathrm{~mm}$ of their neighbors. For both flow cases tested and presented in Fig. 13, searches converged successfully (the design variable fell below $\overline{0.024} \mathrm{~mm}$ tolerance) to reach the target zone, requiring about 94 function evaluations for each case (see Table $\underline{1}$ for the number of objective function evaluations).

\section{Local Optimization}

The local optimization algorithm used a specially developed routine that called on the aerostructural model to evaluate all the points surrounding the best point found during global optimization until the optimum actuation zone was completely delimited. All the points in this optimum zone had an objective function value equal to or smaller than the current optimum, plus an average tolerance of $0.2 \% C_{d}$. A stroke increment of $0.2 \mathrm{~mm}$ was used to sufficiently localize the optimum zone while minimizing the number of evaluations (computation time). The optimal zones and their centers are presented in Fig. 13 for both flow cases. The local optimization method proved to be effective and robust, requiring about 33 objective function evaluations for each case (see Table 1).

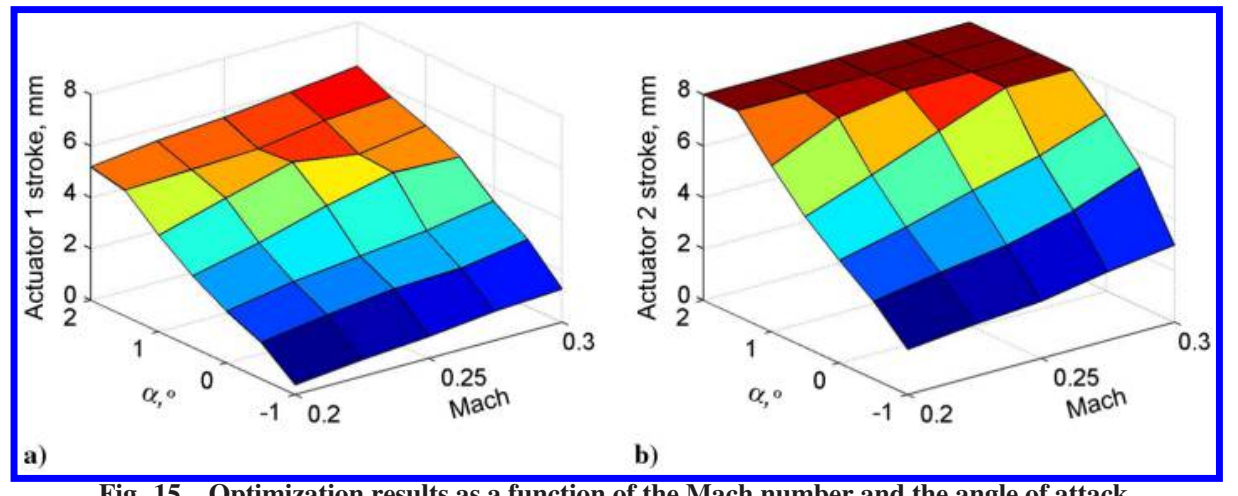

Fig. 15 Optimization results as a function of the Mach number and the angle of attack. 


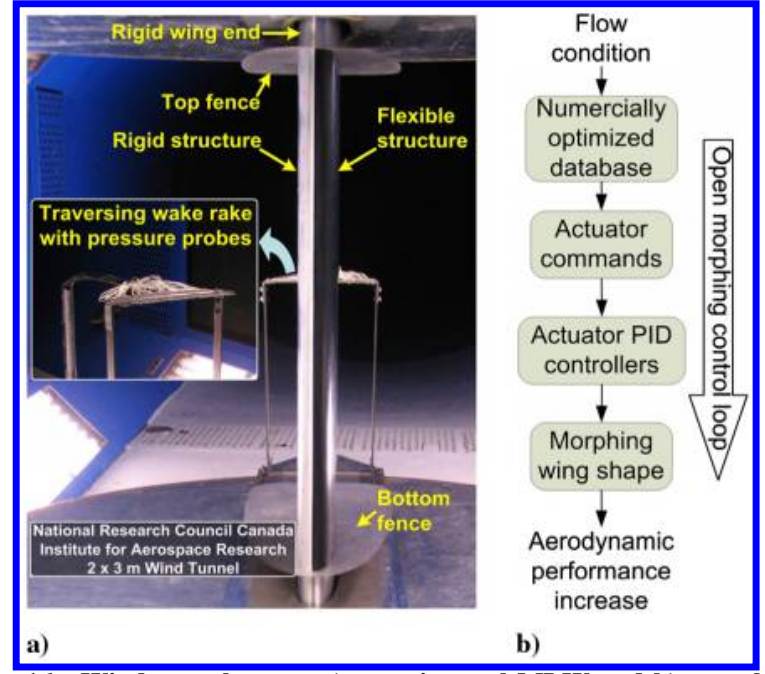

Fig. 16 Wind-tunnel setup: a) experimental MLW and b) open-loop control.

\section{Optimization Results}

For the 35 flow cases, the two-step optimization procedure required 13 times less computation time than the full design search scan. The resulting optimum strokes of two actuators were linearly interrelated up to the second actuator $8 \mathrm{~mm}$ stroke limit (Fig. 14). Note that for both actuators, the higher the Mach number and the angle of attack, the higher the optimum strokes. Finally, an $8 \mathrm{~mm}$ maximum stroke was reached for 15 of the 35 aerodynamic flow cases, which indicates that the full benefits of morphing cannot be exploited using current prototype configuration (see the surface representation of Fig. 15 ).

\section{Wind-Tunnel Validation}

\section{A. Experimental Setup}

The results of numerical optimization were validated on the MLW prototype mounted vertically in the NRC $2 \times 3 \mathrm{~m}$ wind tunnel (Fig. 16a). The wall interference was canceled through proper correction of the experimental data. Two aerodynamic fences were installed on the prototype ends to promote a two-dimensional flow over the wing. However, despite these precautions, wind-tunnel balance measured drag appeared to be about four times greater than that calculated numerically, due to the presence of rigid wing ends and aerodynamic fences. Thus, a traversing wake rake containing 41 total and four static pressure probes was added to measure the drag coefficient more accurately using the momentum method. Two proportional, integral, and derivative (PID) controllers were used to command the actuator strokes using linear potentiometer feedback [10]. For the 35 flow conditions generated in the wind tunnel, openloop MLW control was performed by applying 35 numerically optimized stroke combinations compiled inside a database (Fig. 16b).

\section{B. Morphing Wing Performance}

Wing morphing resulted in a reduced drag under quasi-constantlift conditions. Using balance lift and wake pressure measurements, Fig. 17 presents the morphing test results for eight flow cases covering the flow condition range of interest: Mach 0.2 and 0.3 , with angles of attack varying from -1 to $2^{\circ}$, incremented by $1^{\circ}$. As presented in Figs. 17a and 17b, the measured drag reduction varies between 14.5 and $26.7 \%$, with an average value of $18.5 \%$. Unfortunately, the measured lift forces were found to slightly decrease during morphing (average value of $9 \%$ ), suggesting that the angle-of-attack adjustments (reduction) required to compensate for the lift increase caused by morphing were overestimated. However,

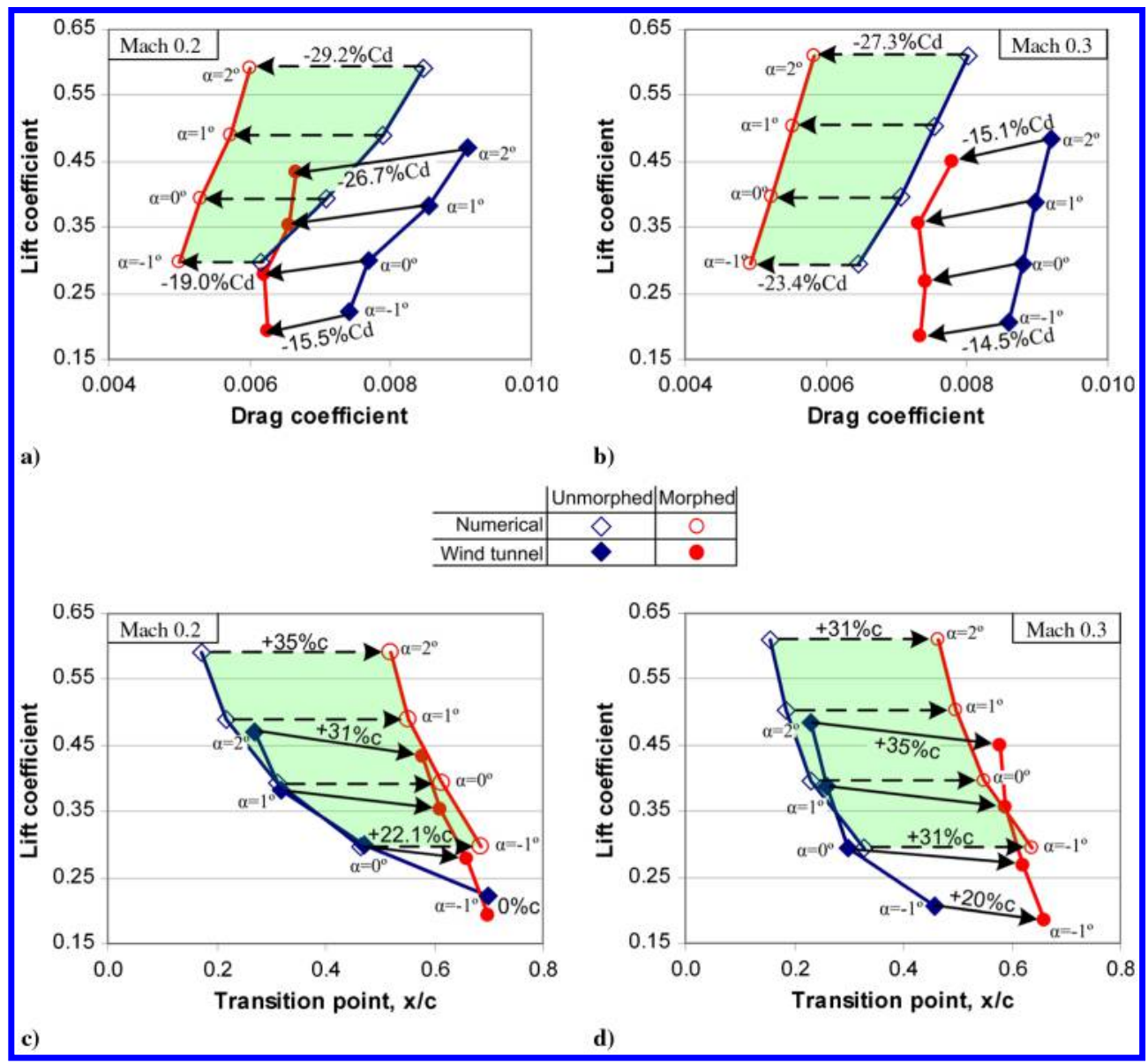

Fig. 17 Numerical and experimental morphing effects over the a-b) aerodynamic lift vs drag coefficients and over the c-d) laminar flow transition for flow conditions ranging from $\alpha=-1$ to $2^{\circ}\left(1^{\circ}\right.$ increments) at a given Mach number (a and c: Mach 0.2; b and d: Mach 0.3). 


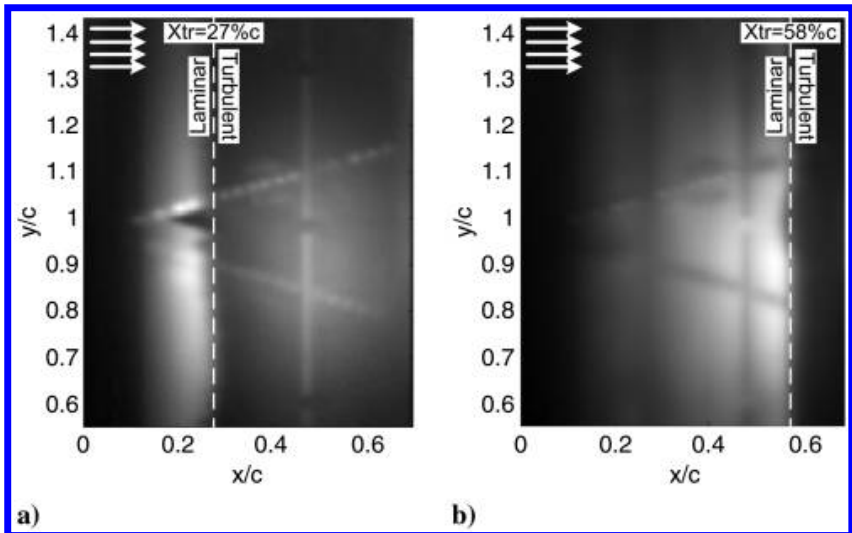

Fig. 18 Laminar/turbulent flow transition over the active structure using IR thermography visualization for Mach 0.2 and $\alpha=2^{\circ}$ : a) unmorphed profile and b) morphed profile.

the considerable shift in the polar curve due to wing morphing proves the effectiveness of open-loop control. In other words, the shape optimization realized with the aerostructural model allows the MLW drag reduction potential to be experimentally validated.

In addition, the IR thermography technique shows that the boundary-layer laminar/turbulent transition location $x_{\text {tr }}$ over the upper surface of the wing is extended toward the trailing edge when the shape is morphed (Figs. 17c and 17d). This effect results in a laminar flow extension from $\overline{0}$ to $35 \% c$, with an average value of $25 \% \mathrm{c}$ for the eight flow conditions. Figure 18 presents a $31 \% \mathrm{c}$ laminar flow regime extension for the Mach $\overline{0.2}$ and $\alpha=2^{\circ}$ flow case, based on the temperature picture comparison of the unmorphed profile $\left(x_{\mathrm{tr}}=27 \% \mathrm{c}\right)$ with the morphed profile $\left(x_{\mathrm{tr}}=58 \% \mathrm{c}\right)$. These IR results, together with the balance and wake rake pressure measurements, prove the feasibility of a significant drag reduction

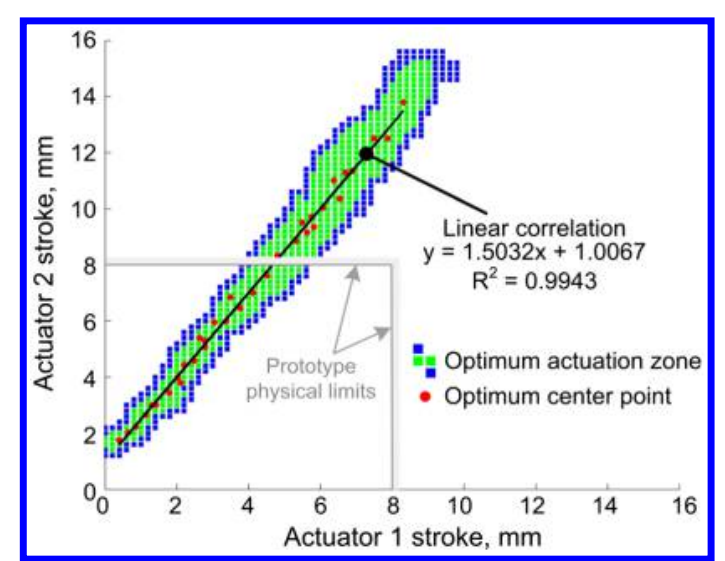

Fig. 19 Optimum strokes for actuators 1 and 2, with no physical limitations of the actuation strokes (to be compared with Fig. 14). (reduction of aircraft fuel consumption and greenhouse gas emission) through the enhancement of the laminar flow regime over the upper surface of an experimental MLW equipped with an active extrados.

C. Discussion of Comparison of Experimental and Numerical Results

The drag reduction obtained during morphing, as well as the laminar flow regime enhancement, was consistent with the numerical predictions, as presented in Fig. 17. However, the numerical aerodynamic coefficients (lift and drag) and the transition point were almost uniformly shifted over the entire test space. For example, the drag measured by the wake rake was greater than that predicted, which can have two possible explanations. It could be explained by the interference of the pressure sensors on the wing surfaces, diminishing the flow velocity measured by the wake rake, or it could be because the two-dimensional aerodynamic solver XFoil does not describe any three-dimensional effects, which reduces the effective angle of attack: the lower the angle of attack, the greater the laminar flow extent over the extrados and the smaller the drag.

XFoil generally gives an optimistic prediction of the laminar flow regime development (Pagès [20]), whereas the calculated laminar flow over the extrados is closer to the leading edge than that experimentally measured by the IR camera. One explanation could be an overestimation of the wind-tunnel turbulence intensity due to the underestimation of the $N$ factor. However, in such a case, the calculated drag and lift forces would have been, respectively, higher and lower than the experimental data, which is not the case. Finally, despite the noticeable differences between the experimental and numerical results, the consistent drag reduction and laminar flow improvement obtained in the wind tunnel prove the reliability of the aerostructural model and its utility for MLW shape optimization.

\section{Beyond Prototype Physical Limitations}

Having determined that a significant improvement of the aerodynamic performance of a morphing wing can be obtained, the following question can now be raised: to what extent do the actuator stroke limitations (maximum stroke of $8 \mathrm{~mm}$ ) affect a wing's optimal aerodynamic performance? To answer this question, the stroke optimization study was repeated without considering the prototype's physical limitations, and the results are presented in Figs. 19 and 20.

If the unmorphed profile is considered as the reference, the unlimited optimization offers better performance than the limited optimization, especially for high Mach numbers (Fig. 21a) and high angles of attack (Fig. 21b), because these conditions are indeed less favorable to maintain a laminar flow regime [22]. However, the gain in drag reduction is relatively small: -30.2 instead of $-27.3 \%$ for the conditions least favorable to laminar flow (Mach 0.3 and $\alpha=2^{\circ}$ ). For the 15 flow cases where actuation strokes exceed $8 \mathrm{~mm}$, the mean relative drag reduction is only improved by less than $1 \%$, a value that might not justify the efforts and complexity related to such a significant extension of the maximum actuator strokes (from 8 to $13.8 \mathrm{~mm})$.

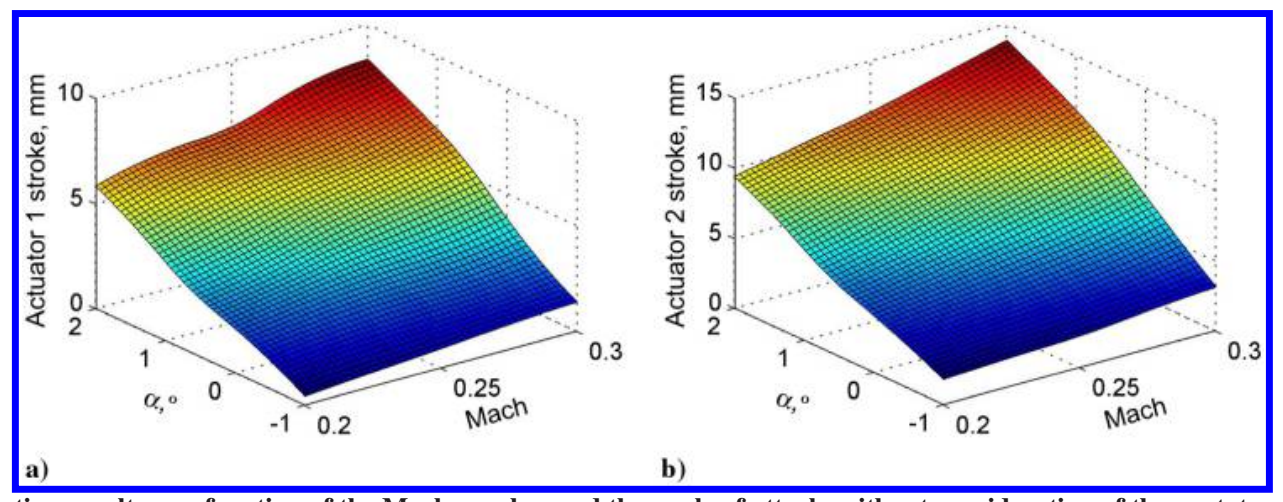

Fig. 20 Optimization results as a function of the Mach number and the angle of attack, without consideration of the prototype's physical limits. 

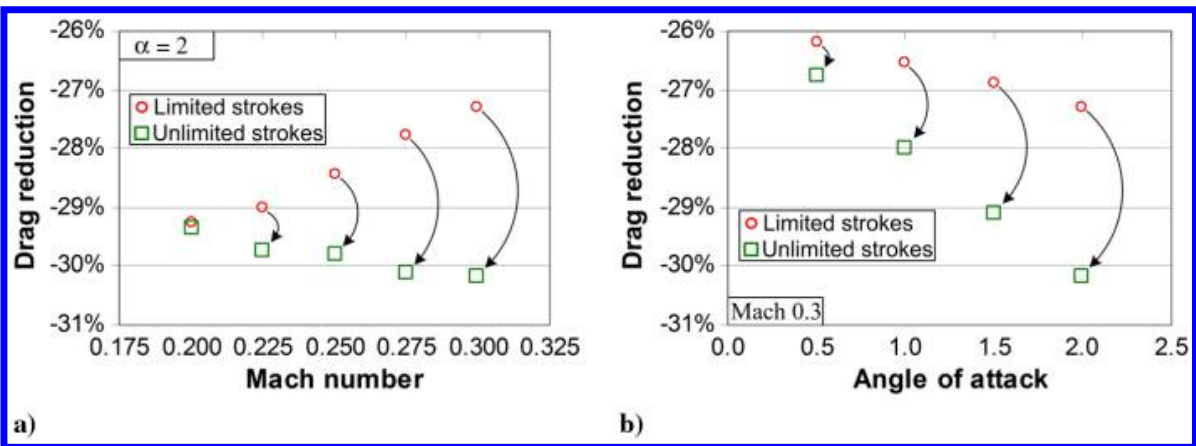

Fig. 21 Relative drag reduction upon morphing from the unmorphed profile for limited and unlimited actuator strokes: a) Mach number variation at $2^{\circ}$ angle of attack, and b) angle-of-attack variation at Mach number 0.3.

\section{Conclusions}

The wind-tunnel optimization of the MLW profile was successfully realized using a coupled aerostructural numerical model. An ANSYS structural FEM of the MLW was first validated under windoff conditions using experimentally measured actuator forcedisplacement characteristics and wing profile modifications. The structural model was then coupled with the XFoil aerodynamic solver, and the aerostructural model was calibrated and validated using experimental wind-tunnel pressure data. Finally, the MLW optimization problem was solved using a two-step search algorithm to determine the optimum actuator strokes to be applied, using an open-loop control approach. The experimental results provided by a wind-tunnel balance, a wake rake, and an IR camera showed a significant aerodynamic performance enhancement in terms of drag reduction and laminar boundary-layer improvement due to wing morphing. A successful comparison of the experimental and numerical results validated the utility of the aerostructural model for an open-loop control of the MLW, despite its inherent limitations to describe miscellaneous three-dimensional aerodynamic effects.

To reduce the difference between the numerical and the experimental results, and thus promote the search for better MLW morphing shapes, the use of a higher fidelity numerical method is recommended. To come closer to applying the MLW concept to a real aircraft, serious consideration of the linear relationship between both actuator strokes presented in Fig. 14 is warranted. In this case, only one actuator connected to a multisegment transmission mechanism could power two or more actuation lines. Also, it was found that actuator strokes vary continuously with respect to the Mach number and angle-of-attack evolution (see the surface of Fig. 15). This particularity allows the use of simple interpolation to feed an openloop controller within a given range of flow conditions. The next step of this project is to develop a closed-loop morphing control strategy using real-time aerodynamic performance feedback signals, such as balance coefficients or IR data, to fully benefit from the potential offered by a MLW. Through the study presented by Coutu et al. $[11,12]$, the aerostructural model serves as an estimator, accelerating the real-time optimizer convergence toward an optimum morphed shape.

\section{Acknowledgments}

The authors would like to thank the Consortium for Research and Innovation in Aerospace in Quebec, the Natural Sciences and Engineering Research Council of Canada, Bombardier Aerospace, and Thales Canada for their financial support. The authors acknowledge the contributions of C. Fischer, S. Bérubé and J.-S. Ratelle to the design and manufacture of the experimental morphing laminar wing prototype used in this study, and those of T. Georges and E. Morellon for their role in experimental testing. Also, the authors thank O. Trifu (currently at CAE. Inc., Montréal) and C. Sainmont from École Polytechnique de Montréal for their collaboration in this work. Finally, the authors acknowledge G.-H. Simon from Thales as the project initiator.

\section{References}

[1] Rutherford, D., and Zeinali, M., "Efficiency Trends for New Commercial Jet Aircraft, 1960 to 2008," [online], International Council on Clean Transportation, Boston, 2009, http://www.nrc-cnrc.gc.ca/eng/ facilities/iar/2x3/technical.html [retrieved 2010].

[2] "The IATA Technology Roadmap Report," [online], 3rd ed., International Air Transport Assoc., Montréal, 2009, p. 50, http://www.iata. org/SiteCollectionDocuments/Documents/Technology_Roadmap_ May2009.pdf [retrieved 10 March 2010].

[3] Thill, C., Etches, J., Bond, I., Potter, K., and Weaver, P., "Morphing Skins," The Aeronautical Journal, Vol. 112, No. 1129, 2008, pp. 117139.

[4] Botez, R. M., Molaret, P., and Laurendeau, E., "Laminar Flow Control on a Research Wing Project Presentation Covering a Three Year Period," 2007 Canadian Aeronautics and Space Institute Annual General Meeting [CD-ROM], Toronto, Canadian Aeronautics and Space Inst., Kanata, ON, Canada, 25-26 April 2007.

-[5] Coutu, D., Brailovski, V., and Terriault, P., "Optimized Design Of An Active Extrados Structure For An Experimental Morphing Laminar Wing," Aerospace Science and Technology, Vol. 14, No. 7, Oct.Nov. 2010, pp. 451-458. doi:10.1016/j.ast.2010.01.009

[6] Coutu, D., Brailovski, V., and Terriault, P., "Promising Benefits of an Active-Extrados Morphing Laminar Wing," Journal of Aircraft, Vol. 46, No. 2, March-April 2009, pp. 730-731. doi:10.2514/1.40657

[7] Sainmont, C., Paraschivoiu, I., and Coutu, D., "Multidisciplinary Approach for the Optimization of a Laminar Airfoil Equipped with a Morphing Upper Surface," Symposium on Morphing Vehicles, NATO AVT-168, Evora, Portugal, 2009.

[8] Popov, A. V., Grigorie, L. T., Botez, R. M., Mebarki, Y., and Mamou, M., "Modeling and Testing of a Morphing Wing in Open-Loop Architecture," Journal of Aircraft, Vol. 47, No. 3, 2010, pp. 917-923. doi:10.2514/1.46480

- [9] Georges, T., Brailovski, V., Morellon, E., Coutu, D., and Terriault, P., "Design of Shape Memory Alloy Actuators for Morphing Laminar Wing with Flexible Extrados," Journal of Mechanical Design, Vol. 131, No. 9, 2009, Paper 091006. doi: $10.1115 / 1.3160310$

[10] Georges, T., Brailovski, V., Morellon, E., Coutu, D., and Terriault, P., "Wind-Tunnel Testing of Shape Memory Alloys Actuators as Morphing Wing Driving Systems," ASME Conference on Smart Material, Adaptive Structures and Intelligent Systems [CD-ROM], American Soc. of Mechanical Engineers, Fairfield, NJ, Sept. 2009.

[11] Coutu, D., Brailovski, V., Terriault, P., Mamou, M., and Laurendeau, E., "Real-Time Optimization of a Research Morphing Laminar Wing in a Wind Tunnel," ASME Conference on Smart Material, Adaptive Structures and Intelligent Systems [CD-ROM], American Soc. of Mechanical Engineers, Fairfield, NJ, Sept. 2009.

[12] Coutu, D., Brailovski, V., Terriault, P., Mamou, M., Mebarki, Y., and Laurendeau, É., "Lift-to-Drag Ratio and Laminar Flow Control of a Morphing Laminar Wing in a Wind Tunnel," Journal of Smart Materials and Structures (submitted for publication).

[13] Love, M. H., Zink, P. S., Stroud, R. L., Bye, D. R., Rizk, S., and White, D., "Demonstration of Morphing Technology Through Ground and Wind Tunnel Tests," 48th AIAA/ASME/ASCE/AHS/ASC Structures, Structural Dynamics and Materials Conference, Waikiki, HI, AIAA Paper 2007-1729, April 2007.

[14] Andersen, G. R., Cowan, D. L., and Piatak, D. J., "Aeroelastic Modeling, Analysis and Testing of a Morphing Wing Structure," 48th 
AIAA/ASME/ASCE/AHS/ASC Structures, Structural Dynamics and Materials Conference, Waikiki, HI, AIAA Paper 2007-1734, April 2007.

[15] Hetrick, J. A., Osborn, R. F., Kota, S., Flick, P. M., and Paul, D. B., "Flight Testing of Mission Adaptive Compliant Wing," 48th AIAA/ ASME/ASCE/AHS/ASC Structures, Structural Dynamics and Materials Conference, Waikiki, HI, AIAA Paper 2007-1709, April 2007.

[16] Strelec, J. K., Lagoudas, D. C., Khan, M. A., and Yen, J., "Design and Implementation of a Shape Memory Alloy Actuated Reconfigurable Airfoil," Journal of Intelligent Material Systems and Structures, Voi. 14, Nos. 4-5, April-May 2003, pp. 257-273. doi: $10.1177 / 1045389$ X03034687

[17] Levinsky, E. S., and Palko, R. L., "Tests of an Improved, ComputerControlled, Self-Optimizing, Variable-Geometry Wing," AIAA Paper 1982-0599, 1982.

[18] Boria, F., Stanford, B., and Ifju, P., "Evolutionary Optimization of a Morphing Wing with Wind-Tunnel Hardware in the Loop," AIAA Journal, Vol. 47, No. 2, Feb. 2009, pp. 399-409. doi: $10.2514 / 1.38941$

[19] Drela, M., "Xfoil: An Analysis and Design System for Low Reynolds
Number Airfoils," Low Reynolds Number Aerodynamics, edited by T. J. Mueller, Lecture Notes in Engineering, Vol. 54, Springer-Verlag, New York, 1989, pp. 1-12.

[20] Pagès, L., "Maximisation de la Laminarité d'un Profil D'aile par Optimisation de la Forme de L'Extrados," M.S. Dissertation, Mechanical Department, École Polytechnique de Montréal, Montréal, 2007.

[21] Trifu, O., Pagès, L., Sainmont, C., and Paraschivoiu, I., "Optimization of the Reference Airfoil and Completion of the CFD Database," École Polytechnique de Montréal Task Rept. 1.6/7, Montreal, Nov. 2007.

[22] Anderson, J. D., "Introduction to the Fundamental Principles and Equations of Viscous Flow," Fundamentals of Aerodynamics, 3rd ed., McGraw-Hill, New York, 2001, pp. 713-744.

[23] Falk, A., Barthold, F. J., and Stein, E., "A Hierarchical Design Concept for Shape Optimization Based on the Interaction of CAGD and FEM," Structural and Multidisciplinary Optimization, Vol. 18, No. 1, Aug. 1999, pp. 12-23. doi:10.1007/BF01210687

[24] MATLAB Genetic Algorithm and Direct Search Toolbox ${ }^{\mathrm{TM}}$, Software Ver. 7.6.0.324 (R2008a), MathWorks, Natick, MA, 2008 
This article has been cited by:

1. Lucian Grigorie, Ruxandra M. Botez, Andrei V. PopovSelf-adaptive morphing wing model, smart actuated and controlled by using a multiloop controller based on a laminar flow real time optimizer . [Citation] [PDF] [PDF Plus]

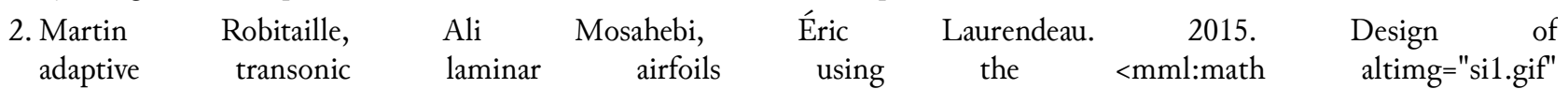
overflow="scroll" $\quad$ xmlns:xocs="http://www.elsevier.com/xml/xocs/dtd" $\quad$ xmlns:xs="http://www.w3.org/2001/ XMLSchema" xmlns:xsi="http://www.w3.org/2001/XMLSchema-instance" $\quad$ xmlns="http://www.elsevier.com/xml/ ja/dtd" xmlns:ja="http://www.elsevier.com/xml/ja/dtd" xmlns:mml="http://www.w3.org/1998/Math/MathML" xmlns:tb="http://www.elsevier.com/xml/common/table/dtd" xmlns:sb="http://www.elsevier.com/xml/common/structbib/dtd" xmlns:ce="http://www.elsevier.com/xml/common/dtd" xmlns:xlink="http://www.w3.org/1999/xlink" xmlns:cals="http://www.elsevier.com/xml/common/cals/dtd" xmlns:sa="http://www.elsevier.com/xml/common/structaff/dtd" $><\mathrm{mml}: \mathrm{mi}>\gamma</ \mathrm{mml}: \mathrm{mi}><\mathrm{mml}: \mathrm{mtext}>-</ \mathrm{mml}: \mathrm{mtext}><\mathrm{mml}: \mathrm{msub}><\mathrm{mml}: \mathrm{mrow}><\mathrm{mml}:$ mover accent="true" $><\mathrm{mml}:$ mrow $><\mathrm{mml}: \mathrm{mi} \quad$ mathvariant="italic" $>\mathrm{Re}</ \mathrm{mml}: \mathrm{mi}></ \mathrm{mml}: \mathrm{mrow}><\mathrm{mml}$ :mrow $><\mathrm{mml}: \mathrm{mo}$ stretchy="false" $></ \mathrm{mml}: \mathrm{mo}></ \mathrm{mml}: \mathrm{mrow}></ \mathrm{mml}$ :mover $></ \mathrm{mml}: \mathrm{mrow}><\mathrm{mml}: \mathrm{mrow}><\mathrm{mml}: \mathrm{mi}>\theta</$

$\mathrm{mml}: \mathrm{mi}><\mathrm{mml}: \mathrm{mi}>\mathrm{t}</ \mathrm{mml}: \mathrm{mi}></ \mathrm{mml}: \mathrm{mrow}></ \mathrm{mml}: \mathrm{msub}></ \mathrm{mml}: \mathrm{math}>$ transition model. Aerospace Science and Technology 46, 60-71. [CrossRef]

3. T. L. Grigorie, R. M. Botez, A. V. Popov. 2015. How the Airfoil Shape of a Morphing Wing Is Actuated and Controlled in a Smart Way. Journal of Aerospace Engineering 28, 04014043. [CrossRef] 